\title{
COMPORTAMENTO DO ÓLEO DE SOJA REFINADO UTILIZADO EM FRITURA POR IMERSÃO COM ALIMENTOS DE ORIGEM VEGETAL ${ }^{1}$
}

\author{
Roseneide C. Ferraz CELLA ${ }^{2}$, Marisa A. B. REGITANO-D’ARCE ${ }^{3, *}$, Marta Helena Fillet SPOTO ${ }^{4}$
}

\begin{abstract}
RESUMO
A fritura é uma operação que confere aos alimentos características de odor, sabor, cor e textura de grande aceitabilidade sensorial. O óleo ou gordura pode, entretanto, se tornar um ingrediente capaz de introduzir alterações químicas provocadas pelo aquecimento prolongado. Neste trabalho, estudou-se o comportamento do óleo de soja refinado em fritura de imersão intermitente, em restaurante universitário, sob temperatura controlada entre $170^{\circ} \mathrm{C}$ e $180^{\circ} \mathrm{C}$, por um período de 30 horas. Foram utilizados 101 litros de óleo de soja para processar $373 \mathrm{~kg}$ de vegetais, como batata, couve-flor, abobrinha e mandioca. Analisou-se o óleo mediante determinações físicas

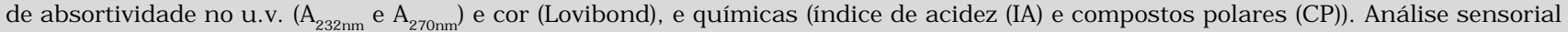
de aceitabilidade foi realizada nos produtos. Os parâmetros-limite que determinaram o descarte do óleo foram: $25 \%$ de compostos polares, $1 \%$ de ácidos graxos livres e média de 7,0 para o teste de aceitabilidade. Os resultados ao final do período foram: IA, 0,282; CP, 18,8\%; cor Lovibond 14Y/2R; $\mathrm{A}_{232 \mathrm{~nm}}$ de 9,213; $\mathrm{A}_{270 \mathrm{~nm}}$ de 2,409 e 7,96 para o teste de aceitabilidade. Com base nos resultados obtidos, concluiu-se que, apesar do aquecimento do óleo ter levado a alteraçoes hidrolíticas e oxidativas, os parâmetros não atingiram o nível de descarte, indicando que o óleo de soja submetido a essas condições de fritura pode ser usado por 30 horas.

Palavras-chave: fritura; óleo de soja; termoxidação; absortividade; compostos polares.
\end{abstract}

\section{SUMMARY}

REFINED SOYBEAN OIL PERFORMANCE IN VEGETABLE DEEP-FAT FRYING. Deep fat frying is an important operation that imparts characteristics of flavor, color and texture in the fried products, however oil or fat becomes an ingredient that induces chemical alterations during prolonged heating periods. The performance of refined soybean oil was studied under intermittent deep fat frying conditions at a university cafeteria, at temperatures between $170^{\circ} \mathrm{C}\left(338^{\circ} \mathrm{F}\right)$ and $180^{\circ} \mathrm{C}\left(356^{\circ} \mathrm{F}\right)$, for a period of 30 hours. During this period, 101 liters of soy oil were used to process $373 \mathrm{~kg}$ of vegetables (potato, cauliflower, squash and cassava). The oil quality was assessed by means of physical ( $u v$ absorptivity $A_{232 n m}$ and $A_{270 n m}$, Lovibond color) and chemical (free fatty acids (FFA) and polar compounds (PC)) determinations. Sensorial analysis in the deep fat fried foods was performed through the acceptability test. The limits for alteration of the oils were established at 27\% PC, 1\% FFA and an average of 7.0 for acceptability. The results obtained at the end of the period were $0.282 \% \mathrm{FFA}, 18.8 \% \mathrm{PC}, 14 \mathrm{Y} / 2 \mathrm{R}$ for Lovibond color, 9.213 for $\mathrm{A}_{232 \mathrm{~nm}}$ and 2.409 for $\mathrm{A}_{270 \mathrm{~nm}}$ and an average of 7.96 for the acceptability test. It can be concluded that the hydrolytic and oxidative alterations induced by the soybean oil under the heating conditions studied did not warrant discarding the oil after 30 hours.

Keywords: frying; soybean oil; termoxidation; absorptivity; polar compounds.

\section{1 - INTRODUÇÃO}

O processo de fritura desenvolve características de odor, sabor, cor e textura que tornam os alimentos mais atraentes para o consumo [11]. Além disso, considerando que uma parte do óleo utilizado como meio de transferência de calor é absorvida pelo alimento, tornando-se um ingrediente do produto, verifica-se a necessidade do uso de um meio de fritura de alta qualidade e a manutenção desta por períodos mais longos possiveis.

A principal razão que leva o processo de fritura a ser destacado é que, durante o processo, não só o óleo se incorpora ao alimento para modificar positivamente suas propriedades nutricionais e sensoriais, como também atua como meio de transferência de calor reutilizável, muito mais eficiente que o forneamento e muito mais rápido que o cozimento em água. Assim, as altas temperaturas que se utilizam, ao redor de $180^{\circ} \mathrm{C}$, produzem uma acelerada penetração de calor, levando a uma rápida elaboração dos alimentos, algo sumamente necessário nestes tempos modernos [9].

Estudos com óleos aquecidos por longos períodos, sob temperaturas extremamente elevadas, demonstraram que os produtos resultantes contém mais de 50\% de compostos polares, que são os produtos de degradação dos triglicerídios (polímeros, dímeros, ácidos graxos livres, diglicerídeos e ácidos graxos oxidados). Óleos com altos teores de compostos polares provocaram severas irritações do trato gastrointestinal, diarréia, redução no crescimento e, em alguns casos, morte de animais em laboratório [3].

Não há uma única maneira de definir quando descartar um óleo de fritura. Vários alimentos são fritos em diferentes tipos de óleo, em diversos tipos de fritadeiras e sob condições diferentes de operação, que determinam velocidades de degradação maior ou menor. Portanto um método específico pode ser bom para avaliar um determinado sistema e não ser aplicável a outro [8, 16, 21].

\footnotetext{
${ }^{1}$ Recebido para publicação em 03/10/00. Aceito para publicação em 03/01/02. Parte da dissertação de Mestrado em Ciência e Tecnologia de Alimentos (ESALQ/USP) do primeiro autor.

${ }^{2} \mathrm{ESALQ/USP}$

${ }^{3}$ Departamento de Agroindústria, Alimentos e Nutrição - ESALQ/USP, C.P.09, CEP13.418-900 Piracicaba, SP. E-mail para correspondência: mabra@esalq.usp.br

${ }^{4}$ CENA/USP

* A quem a correspondência deve ser enviada.
} 
O objetivo desta pesquisa foi acompanhar, através de análises químicas, físicas e sensoriais, as alterações no óleo de soja, durante a fritura de vegetais, em restaurante universitário e com base nesses dados, verificar a hora adequada de descarte.

\section{2 - MATERIAL E MÉTODOS}

O óleo selecionado para o estudo foi o de soja, obtido de uma indústria nacional, em latas de $900 \mathrm{~mL}$. A fritura foi conduzida em fritadeira elétrica de aço inoxidável, com capacidade total de 60 litros, dividida em dois compartimentos, com cestos de aço inoxidável, em temperatura inicial entre $170^{\circ} \mathrm{C}$ a $180^{\circ} \mathrm{C}$, por 30 horas. $\mathrm{O}$ cardápio do restaurante universitário da Escola Superior de Agricultura "Luiz de Queiroz" da Universidade de São Paulo (ESALQ - USP), foi reformulado para adaptar-se ao estudo. Diariamente foram preparadas 850 refeições entre almoço e jantar. Além do próprio termostato da fritadeira, a temperatura do óleo foi acompanhada com auxílio de termômetro.

A adição de óleo novo foi feita sempre que necessária, para manter o nível constante na fritadeira, visando o bom funcionamento do equipamento e garantindo uma boa apresentação e qualidade do alimento servido.

Todos os vegetais foram submetidos ao pré-preparo que incluiu: limpar, descascar, fatiar, picar, seguidos de imersão em água fria e retiradas para drenar o excesso de água, minutos antes da fritura.

Foram utilizados 112 latas de $900 \mathrm{~mL}$ que correspondem a 101 litros de óleo de soja, para fritar 373Kg de alimentos: mandioca cozida $(4,3 \%)$, couve-flor cru à doré (16\%), abobrinha à doré (13\%) e batata in natura com corte tipo chips (66,7\%). Para as preparações à doré foram utilizados leite, ovos e farinha de trigo para empanar.

Após o término de cada fritura, o óleo da fritadeira foi filtrado, através de um tecido de algodão para reter toda os resíduos sólidos em suspensão e acondicionado em galões, não transparentes, armazenados à temperatura ambiente, aguardando a próxima fritura. A freqüência desta fritura foi semanal. Logo após cada filtração, uma amostra de óleo foi coletada e acondicionada em frasco de vidro âmbar com tampa e capacidade de $20 \mathrm{~mL}$, guardado em congelador para posterior análise. A Tabela 1 apresenta o tempo de utilização e os vegetais empregados na fritura.

As análises químicas e físicas foram conduzidas respectivamente, pelas seguintes metodologias, índice de acidez, AOCS - Ca 5a-40 [1], compostos polares, IUPAC - 2507 [19] com uma pequena modificação, proposta por DOBARGANES et al. [6], absortividade em 232nm e $270 \mathrm{~nm}$ realizado em espectrofotômetro Shimadzu, modelo UV 1203, método IUPAC [18] e a varredura foi realizada através do programa "Personal Spectroscopy" versão 1.1, cor Lovibond - AOCS Cc 13b-45 [2].

$\mathrm{O}$ teste de aceitabilidade realizou-se no restaurante universitário da ESALQ, no horário do almoço $(11 \mathrm{~h} \mathrm{-}$ 13h). Para a execução desse teste são normalmente necessários de 25 a 50 provadores, não treinados. Os comensais que foram escolhidos aleatoriamente, preencheram uma ficha que era devolvida após a refeição. Participaram dos testes provadores não treinados de ambos os sexos. Foi utilizada uma escala hedônica de 9 pontos ancorados em seus extremos nos termos gostei muitíssimo (9) e desgostei muitíssimo (1). Calculou-se o indice de aceitabilidade, onde a nota máxima (9) correspondeu a $100 \%$ de aceitabilidade, e a média definiu o indice de aceitabilidade. Também foram realizados inquéritos sobre freqüência, forma e local de consumo do alimento.

TABELA 1. Tempo de utilização e os vegetais empregados na fritura.

\begin{tabular}{llcccc}
\hline $\begin{array}{c}\text { Fritura } \\
\text { no }\end{array}$ & Vegetais fritos & Quantidade $(\mathrm{kg})$ & T.F & T.A & $\begin{array}{c}\text { Reposição } \\
\text { Latas/litros(L) }\end{array}$ \\
\hline 01 & Mandioca cozida & 16 & $45 \mathrm{~min}$ & $45 \mathrm{~min}$ & 60 latas/56L \\
02 & Couve-flor à doré & 60 & $4 \mathrm{~h} 40 \mathrm{~min}$ & & - \\
& Abobrinha à doré & 16 & $1 \mathrm{~h} 10 \mathrm{~min}$ & $6 \mathrm{~h} 35 \mathrm{~min}$ & - \\
03 & Batata chips & 55 & $4 \mathrm{~h} 20 \mathrm{~min}$ & $10 \mathrm{~h} 55 \mathrm{~min}$ & 4 latas/3,6L \\
04 & Batata chips & 52 & $4 \mathrm{~h} 30 \mathrm{~min}$ & $15 \mathrm{~h} 25 \mathrm{~min}$ & 13 latas/11,7L \\
05 & Batata chips & 50 & $3 \mathrm{~h} 55 \mathrm{~min}$ & $19 \mathrm{~h} 20 \mathrm{~min}$ & 9 latas/8,1L \\
06 & Abobrinha à doré & 16 & $2 \mathrm{~h} 05 \mathrm{~min}$ & $21 \mathrm{~h} 25 \mathrm{~min}$ & - \\
07 & Batata chips & 46 & $3 \mathrm{~h} 50 \mathrm{~min}$ & $25 \mathrm{~h} 15 \mathrm{~min}$ & 10 latas/9L \\
08 & Batata chips & 46 & $4 \mathrm{~h} 20 \mathrm{~min}$ & $29 \mathrm{~h} 35 \mathrm{~min}$ & 8 latas/7,2L \\
09. & Abobrinha à doré & 16 & $1 \mathrm{hora}$ & $30 \mathrm{~h} 35 \mathrm{~min}$ & 8 latas/7,2L \\
\hline
\end{tabular}

TF: tempo de utilização do óleo em cada fritura

TA: tempo acumulado de utilização do óleo de fritura

Para análise estatística, dos dados do teste de aceitabilidade, foi adotado um delineamento experimental, em blocos ao acaso. Os dados foram calculados utilizando o programa SANEST e avaliados através do teste F, da análise da variância e do teste Tukey [14].

\section{3 - RESULTADOS E DISCUSSÃO}

A pesquisa compreendeu 09 frituras, sendo que, cada uma delas foi executada em dia diferente, conforme o cardápio do restaurante.

TABELA 2. Características do óleo de soja da fritura de vegetais

\begin{tabular}{cccccccc}
\hline $\begin{array}{c}\text { Fritura } \\
\text { № }\end{array}$ & $\begin{array}{c}\text { Tempo } \\
\text { acumulado }\end{array}$ & $\begin{array}{c}\text { Acidez } \\
\text { \% oléico }\end{array}$ & $\begin{array}{c}\text { Compostos } \\
\text { polares } \%\end{array}$ & $\begin{array}{c}\text { Cor Lovibond } \\
\text { Y/R }\end{array}$ & $\mathrm{A}_{232 \mathrm{~nm}}$ & $\mathrm{~A}_{270 \mathrm{~nm}}$ & R.L \\
\hline Controle & & 0,0570 & $6,0 \%$ & $1,3 / 0,2$ & 4,187 & 1,473 & \\
01 & $45 \mathrm{~min}$ & 0,1079 & 10,1 & $2,0 / 0,3$ & 4,741 & 1,585 & \\
02 & $6 \mathrm{~h} 35 \mathrm{~min}$ & 0,2598 & 19,3 & $11,0 / 1,3$ & 5,175 & 1,757 & \\
03 & $10 \mathrm{~h} 55 \mathrm{~min}$ & 0,3491 & 21,6 & $13,0 / 2,0$ & 6,144 & 2,040 & 4 \\
04 & $15 \mathrm{~h} 25 \mathrm{~min}$ & 0,2832 & 20,1 & $11,0 / 1,7$ & 6,217 & 2,045 & 13 \\
05 & $19 h 20 \mathrm{~min}$ & 0,2693 & 19,1 & $9,9 / 1,7$ & 6,945 & 2,025 & 9 \\
06 & $21 \mathrm{~h} 25 \mathrm{~min}$ & 0,2695 & 20,5 & $9,9 / 1,5$ & 9,497 & 2,276 & \\
07 & $25 \mathrm{~h} 15 \mathrm{~min}$ & 0,3264 & 18,5 & $15,0 / 2,7$ & 9,516 & 2,302 & 10 \\
08 & $29 h 35 \mathrm{~min}$ & 0,3230 & 19,2 & $13,0 / 2,2$ & 10,134 & 2,515 & 8 \\
09 & $30 h 35 \mathrm{~min}$ & 0,2820 & 18,8 & $14,0 / 2,0$ & 9,123 & 2,293 & 8
\end{tabular}

R.L. reposição em latas. 
A fritura 01 iniciou nos dois compartimentos da fritadeira, comportando 54 litros de óleo. Ao final da fritura 02, o óleo restante foi acondicionado em apenas um dos compartimentos para finalizar a fritura do dia, e o estudo continuou em apenas um compartimento até o final desta pesquisa. Na Tabela 2 encontram-se os resultados das análises químicas e físicas do óleo de soja ao longo das 30 horas e 35 minutos de fritura.

\section{1 - Acidez}

$\mathrm{O}$ índice de acidez, no segundo dia do estudo, representada pela fritura 02 , apresentou um incremento mais significativo. $\mathrm{O}$ aumento ou diminuição do índice de acidez refletiu o tempo de fritura e a diluição pela adição de óleo novo. O aumento da acidez indica o desenvolvimento de reações hidrolíticas, com a produção de ácidos graxos livres, e conseqüentemente, de diglicerídeos, que ocorreu devido à presença de água e da alta temperatura, pois, quanto maior o percentual de água no alimento, mais rapidamente ela ocorre.

Seguindo a legislação dos Estados Unidos, o mais exigente dos países, quanto à qualidade do óleo de fritura, o valor máximo para índice de acidez é de $1 \%$ [7]. A Figura 1 apresenta a progressão da hidrólise do óleo nesta fritura.

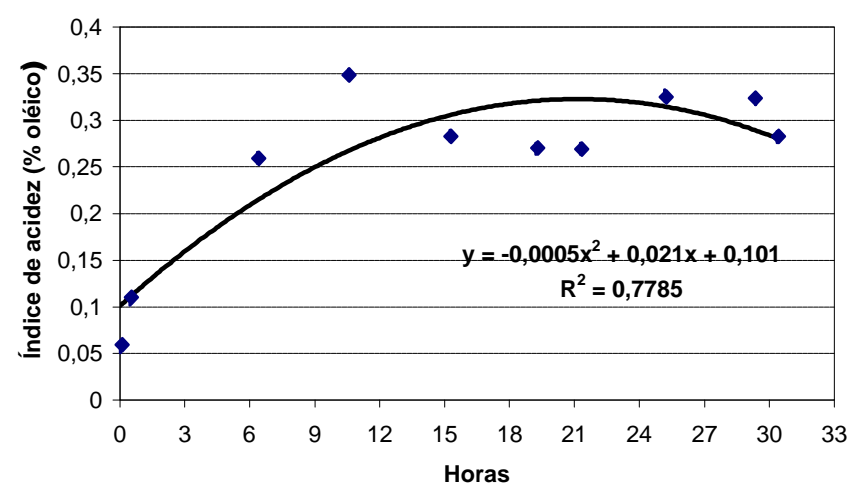

FIGURA 1. Índice de acidez em \% oléico no óleo da fritura de vegetais.

Pode-se observar que em 6h35min ocorreu um acréscimo da acidez e na seqüência, mesmo com a reposição de 4 latas de óleo, o processo de hidrólise continuou. A partir das $10 \mathrm{~h} 55 \mathrm{~min}$, a alta rotatividade de óleo novo deve ter colaborado para manter baixo o aumento da acidez. Neste tipo de fritura, a velocidade de reposição de óleo fresco para compensar o óleo absorvido pelo produto frito, afeta muito a qualidade do óleo, fazendo flutuar os índices de qualidade.

Em ensaio de fritura de batatas chips, em fritadeira elétrica com reposição de óleo constante, obteve-se uma boa correlação entre ácidos graxos livres, compostos polares totais e tempo de fritura [9].

A análise de ácidos graxos livres seria um parâmetro rápido e simples para controle da alteração do sistema analisado, se esta relação não se alterasse com a matéria-prima utilizada [16].

\section{2 - Compostos polares}

A determinação dos compostos polares totais tem sido reportada por vários autores como um dos melhores métodos para determinação do estado de alteração do óleo de fritura $[12,20]$. Várias metodologias foram testadas para a determinação de compostos polares totais em óleos de fritura. O método de separação em coluna cromatográfica, usando sílica como adsorvente, é um método rápido, fácil de ser realizado, que permite boa separação entre triglicerídeos não alterados e o material polar visto que, ainda, existe uma boa correlação entre o grau de deterioração do óleo e o teor de compostos polares totais determinado por este método [5].

$\mathrm{O}$ ato de fritar um alimento como, por exemplo, a batata que contém água intrínseca, e extrínseca oriunda do pré-preparo, exerce um efeito deteriorativo ainda maior sobre o óleo aquecido [13].

Pode-se observar que a porcentagem de compostos polares totais elevou-se em apenas 45 minutos de fritura, demonstrando que o aquecimento, mesmo em período curto é prejudicial para o óleo.

No final do segundo dia desta fritura, este índice teve um acréscimo significativo. Depois deste período apresentou pequenas alterações provocadas pela adição de óleo novo, necessária para repor o óleo absorvido pelo alimento.

Alguns autores também verificaram que a alta reposição de óleo fresco, isto é, a freqüente rotatividade de óleo fresco, evita que o nível de $25 \%$ de compostos polares seja alcançado [5]. O limite do teor de compostos polares para descartar um óleo de fritura aceito pela Espanha é de 25\% [9]. No presente estudo, o valor máximo manteve-se entre $18 \%$ e $21 \%$ por mais de 30 horas. A Figura 2 apresenta a evolução dos compostos polares nesta fritura.

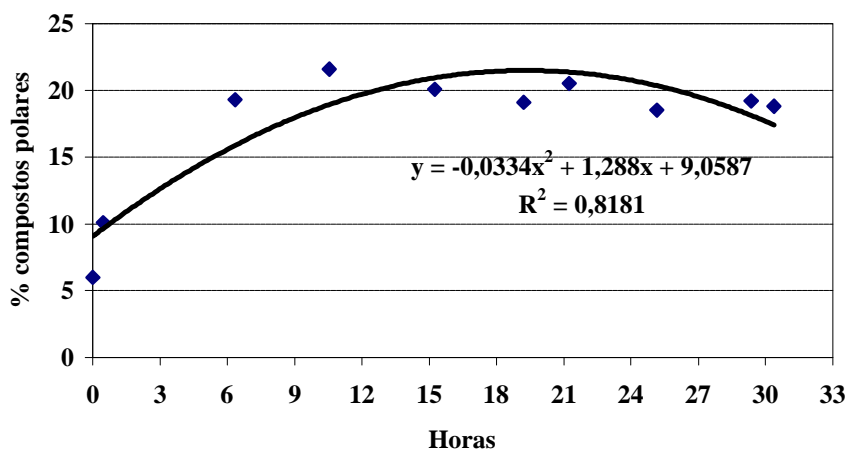

FIGURA 2. Comportamento dos compostos polares na fritura de vegetais.

A Figura 3 apresenta a correlação entre o índice de acidez (\% em oléico) e o teor de compostos polares nesta fritura.

$\mathrm{O}$ valor de $\mathrm{R}^{2}(0,9642)$ confirma a boa correlação existente entre o índice de acidez e compostos polares neste tipo de fritura, conforme já verificado em outros estudos. 


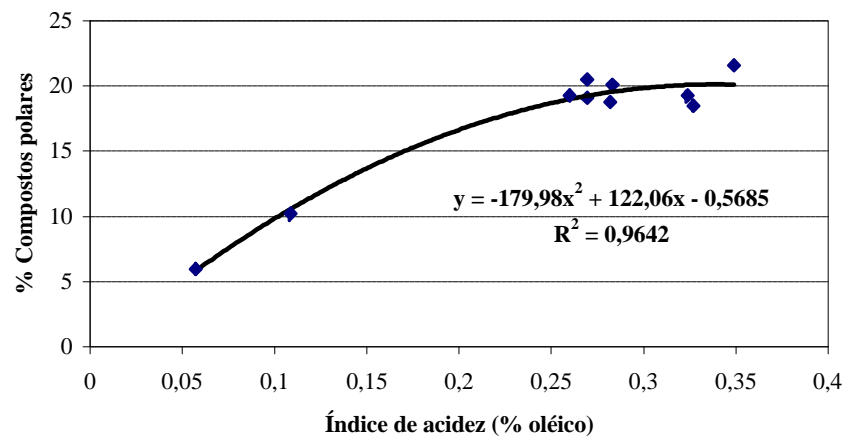

FIGURA 3. Correlação entre o teor de compostos polares e o indice de acidez.

\section{3 - Absortividade na faixa do ultravioleta}

Alguns produtos da oxidação apresentam valores máximos de absorção em determinado comprimento de onda. Os compostos primários da oxidação apresentam valores máximos de absortividade na faixa entre $220 \mathrm{~nm}$ e 234nm (dienos). A partir de 265nm são os compostos secundários da oxidação (trienos, aldeídos, cetonas) que apresentam maior absorção [15].

O acompanhamento dos espectros de absortividade na faixa do ultravioleta das amostras do óleo forneceu boa indicação das alterações que ocorreram durante o processo oxidativo, visto que o índice de peróxido não pode ser utilizado por não refletir o aumento da degradação do óleo com o tempo de fritura. Por serem instáveis, os peróxidos são rapidamente formados e quebrados em compostos menores, porém os dienos conjugados que se formam concomitantemente, permanecem. A Figura 4 apresenta os espectros de absortividade dos óleos ao final de cada período da fritura.

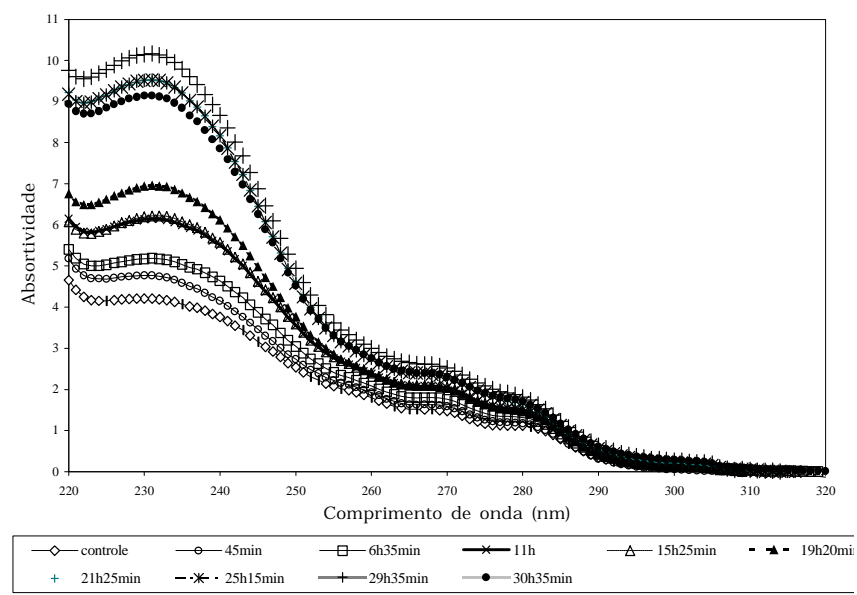

FIGURA 4. Espectro de absortividade na faixa do UV dos óleos de fritura de vegetais.

Os espectros de absortividade apresentados na $\mathrm{Fi}$ gura 4, indicam que o aquecimento próximo de $170^{\circ} \mathrm{C}$, por 29 h35min, promoveu aumento crescente nos valores de absortividade na faixa de $232 \mathrm{~nm}$. O período de 21 h25min, que não sofreu reposição apresentou um acréscimo mais acelerado. No último período de estudo que finalizou com 30h35min de fritura, a adição de 8 latas, correspondendo a $26,6 \%$ de óleo fresco, ocasionou uma redução dos valores encontrados na absortividade em $232 \mathrm{~nm}$, como pode ser verificado através da análise da curva.

Através das curvas do espectro traçado na faixa de 220 a 320nm para todas as amostras testadas foi possivel acompanhar as alterações ocorridas.

\section{4 - Cor Lovibond}

A cor do óleo depende da qualidade do refino e dos alimentos que se fritam. Quando óleos muito insaturados como o de soja são aquecidos ocorre isomerização e migração de duplas ligações, levando à conjugação das mesmas. A conjugação de duplas ligações leva à absorção de quantidades maiores de luz azul, provocando um aumento de cores laranja e marrom no óleo. Portanto, a cor do óleo irá depender do teor inicial de duplas ligações e dos alimentos que se fritam [10].

Além disso ocorre a absorção ou passagem dos pigmentos escuros dos alimentos para o óleo e também o escurecimento do alimento devido às reações de Maillard, dentre outras. A Tabela 1 apresentou os resultados. A Figura 5 apresenta a progressão das cores Y e R nesta fritura.

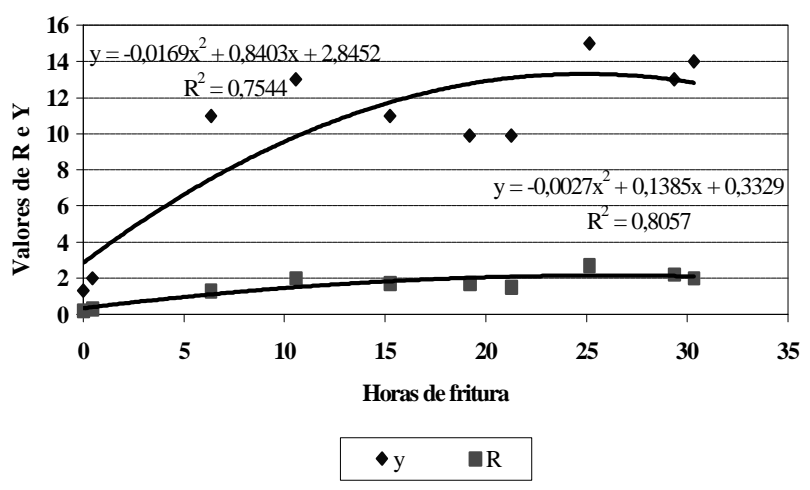

FIGURA 5. Cor Lovibond $Y$ e R do óleo da fritura de vegetais

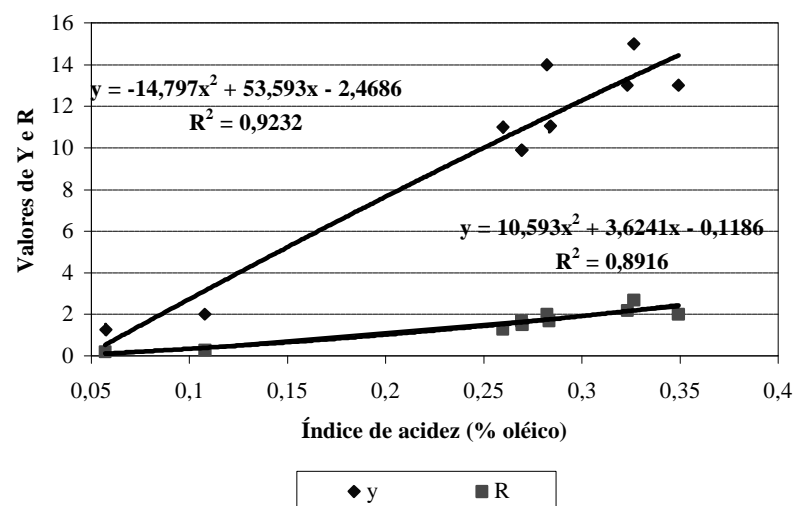

FIGURA 6. Correlação existente entre índice de acidez e cor Lovibond Y e R. 
Graficamente a correlação polinomial reflete a oxidação do óleo através da acentuação da cor amarela e vermelha e perda da qualidade.

Os valores de Y e R apresentaram uma boa correlação com o índice de acidez, os valores de Y com coeficientes de correlação mais altos do que R, conforme mostra a Figura 6.

\section{5 - Análise sensorial}

O teste de aceitabilidade dos alimentos fritos de origem vegetal foi conduzido em 6 períodos, cada período correspondeu às seguintes horas acumuladas das frituras: 6h35min (fritura 02), 10h55min (fritura 03), 15h25min (fritura 04), 19h20min (fritura 05), 25h 15min (fritura 07), 29h35min (fritura 08). Como o valor de $\mathrm{F}$ foi significativo, apresentando valor igual 3,94, em nível de $5 \%$ de probabilidade, realizou-se o teste Tukey. Os resultados estão apresentados na Tabela 3.

TABELA 3. Médias das notas do teste de aceitabilidade da fritura de vegetais

\begin{tabular}{cc}
\hline Período & Médias \\
\hline 1 (fritura 02) & $8,20^{\mathrm{a}}$ \\
2 (fritura 03) & $7,50 \mathrm{bc}$ \\
3 (fritura 04) & $7,69 \mathrm{abc}$ \\
4 (fritura 05) & $7,19 \mathrm{c}$ \\
5 (fritura 07) & $7,73 \mathrm{abc}$ \\
6 (fritura 08) & $7,96 \mathrm{ab}$ \\
\hline
\end{tabular}

Médias seguidas por letras distintas diferem entre si em nivel de 0,05 de significância

A Figura 7 apresenta a média das notas dos provadores em relação às horas acumuladas que estão representadas por períodos dos alimentos fritos.

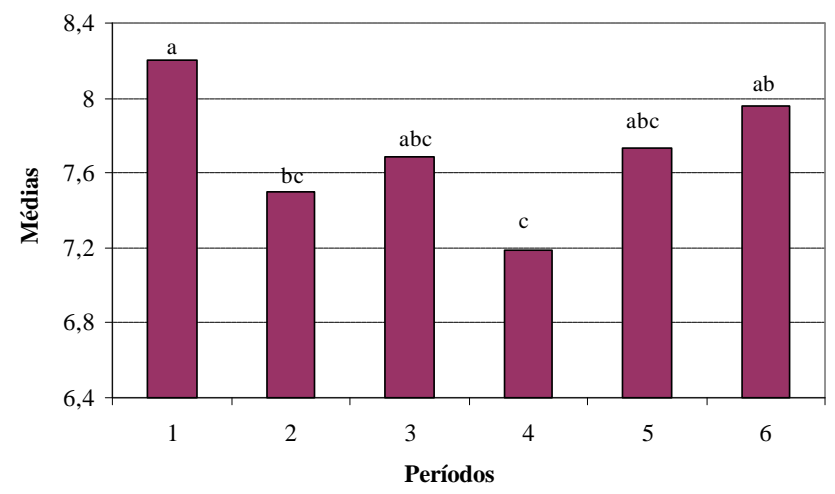

FIGURA 7. Comportamento dos provadores em relação à aceitabilidade da fritura de vegetais

Observa-se pela Tabela 3, que durante todo o período das frituras, as notas oferecidas pelos provadores estiveram dentro do intervalo de "gostei muito", a "gostei moderadamente". A nota mais alta foi observada pelos provadores no $1^{\circ}$ período. Entretanto, não foram observadas alterações aparentes nos vegetais submeti- dos às frituras dos demais períodos, quando comparadas com o primeiro período. Em todos os períodos, foram observados os atributos "seco" e "crocante" de textura, somente alguns provadores observaram os atributos "encharcada" e "oleosa", nos períodos 2,3 , e 4, e ainda assim, caracterizando-se como "um pouco encharcada" ou "um pouco oleosa". Podem-se caracterizar esses atributos, como os responsáveis pela ligeira diminuição das notas dos provadores.

Quanto ao sabor e aroma dos alimentos fritos, os provadores foram unânimes em observar os atributos "leve", "suave" e "característico de fritura" e "sem cheiro ou gosto de óleo de fritura”. Interessante observar, que o atributo "ranço", o qual era esperarado, não apareceu em nenhum período do experimento, mesmo nos últimos períodos de fritura, os quais não diferiram significativamente do primeiro período (Figura 7).

Para que um produto seja considerado como aceito, em termos de suas propriedades sensoriais, é necessário que se obtenha um índice de aceitabilidade de no mínimo 70\% [17]. As características sensoriais determinam a aceitabilidade ou não de um produto. Os atributos sensoriais, tais como cor, odor, textura e o sabor entre outros, são fatores que influenciam a utilização em vários produtos, sendo que o sabor é a mais importante propriedade na determinação da aceitabilidade de um alimento [4].

\section{4 - CONCLUSÕES}

- As determinações analíticas foram úteis para acompanhar a oxidação. Os resultados se apresentaram dentro dos limites aceitos pela regulamentação da Espanha e dos EUA.

- Sensorialmente o alimento frito foi bem aceito pelos provadores até o final do experimento.

- Para as condições do ensaio, isto é, capacidade e modelo da fritadeira, temperatura controlada, origem do alimento, freqüência da reposição de óleo novo, acondicionamento do óleo usado, pode-se recomendar o uso desse óleo por 30 horas.

\section{5 - REFERÊNCIAS BIBLIOGRÁFICAS}

[1] A.O.C.S.- AMERICAN OIL CHEMISTS' SOCIETY. Official and tentative methods. 3a, ed. Champaign;, 1983.

[2] A.O.C.S.- AMERICAN OIL CHEMISTS' SOCIETY. Official methods and recommended practices., 4 a .ed. Champaign, 1989. p. irreg.

[3] BILLEK.G. Heated fats in the diet. In: PADLEY, F. B.; PODMORE. $J$ (Eds). The role of fats in human nutrition. Chichester: Ellis Horwood, 1985. cap. 12, p. 163-172.

[4] CHAIB, M.A. Métodos para avaliação sensorial dos alimentos. 4 ed. Campinas: Unicamp, 1983, 62p.

[5] CUESTA, C., MUÑIZ, S.F.J. Quality control during repeated fryings. Grasas y Aceites, v. 49,n.3-4, p. 310- 318, 1998.

[6] DOBARGANES, M.C., PEREZ-CAMINO, M.C., GUTIÉRREZGONZÁLES, R. Métodos analíticos de aplicación en grasas calentadas. I Determinación de ésteres metílicos no alterados. Grasas y Aceites, v. 35, n. 3, p. 172-177, 1984. 
[7] FIRESTONE, D., STIER, R.F., BLUMENTHAL, M.M. Regulation of frying fats and oils. Food Technology, v. 45, n. 2, p. 90-94, 1991.

[8] FRITSCH, C.W. Measurements of frying fat deterioration: a brief review. Journal of the American Oil Chemists' Society. v.5, n. 3, p. 272-274, 1981.

[9] JORGE, N. Estudos do comportamento do óleo de girassol e do efeito do dimetil polisiloxano em Frituras. Campinas, 1996. 233p. Tese (Doutorado). Faculdade de Engenharia de Alimentos, Universidade Estadual de Campinas.

[10] LIMA, J.R.; GONÇALVES, L.A.G. Avaliação da qualidade de óleo de soja utilizado para fritura. Campinas, 1994. 60p. Tese (Mestrado). Faculdade de Engenharia de Alimentos, Universidade Estadual de Campinas.

[11] O'DONNELL, C.D. Fats and oils: forces in fried food quality. Prepared Foods, 77-78, 1995.

[12] PÉREZ-CAMINO, M.C., MÁRQUES-RUIZ, G., SALGADO-RAPOSO,A., DOBARGANES, M.C., Alteración de grasas usadas en fritura III. Correlación entre indices analíticos y métodos de evaluación directa de compuestos de degradación. Grasas y Aceites, v. 39, n. 2, p. 72-76, 1988.

[13] PERKINS, E,G. \& AKKEREN, V. L.A. Heated fats. IV. Chemical changes in fats subjected to deep fat frying processes: cottonseed oil. Journal American Oil Chemists' Society, v. 42, n. 9, p. 782-786, 1965.
[14] PIMENTEL, G.F., Curso de estatística experimental. 13.ed: Piracicaba: Nobel, 1990. 468p.

[15] SHAHIDI, F. Stability of fats and olis. In: LATIN AMERICAN CONGRESS AND EXHIBIT ON FATS AND OILS PROCESSINGS, 6., Campinas, 1995. Proceedings. Campinas: Sociedade Brasileira de Óleos e Gorduras, 1995. p.47-54.

[16] STEVENSON, S.G.; VAISEY-GENSER, M.; ESKIN, N. A.M. Quality control in the use of deep frying oils. Journal of the Americam Oil Chemists' Society, v. 61, p. 1102-1108, 1984.

[17] Teixeira, E; Meinert. E, BArbeta, P. A. Análise sensorial dos alimentos. Florianópolis: ed da UFSC, 1987, 180p.

[18] INTERNATION UNION OF PURE AND APPLIED CHEMISTRY. Standard methods for the analysis of oils, fats and derivatives. $6^{\mathrm{a}}$ ed. Oxford, IUPAC, 1979.

[19] INTERNATION UNION OF PURE AND APPLIED CHEMISTRY. Standard methods for the analysis of oils, fats and derivatives. $7^{\mathrm{a}}$ ed. Boston, method 2507, IUPAC, 1987.

[20] WESSELS, H. Results of a collaborative study on determination of polar compounds in frying fats. Pure \& Applied Chemistry. v.55, n. 8, p. 1381-1385, 1983.

[21] WHITE, P. J. Methods for measuring changes in deepfat frying oils. Food Technology, v. 45,n.2, p. 7580,1991 . 